\title{
AVALIAÇÃO DO PROGRESSO GENÉTICO OBTIDO EM 22 ANOS NO MELHORAMENTO DO ARROZ IRRIGADO EM MINAS GERAIS'
}

\author{
PATRÍCIA GUIMARÃES SANTOS ${ }^{2}$, PLIINIO CÉSAR SOARES ${ }^{3}$, ANTÔNIO ALVES SOARES ${ }^{4}$ \\ ORLANDO PEIXOTO DE MORAIS ${ }^{5}$ e VANDA MARIADE OLIVEIRA CORNÉLIO ${ }^{6}$
}

\begin{abstract}
RESUMO - O objetivo deste trabalho foi avaliar o desempenho do programa de melhoramento genético do arroz irrigado, no Estado de Minas Gerais. Foram utilizados os dados de produtividade de grãos dos ensaios comparativos avançados de cultivares e linhagens de arroz irrigado, conduzidos em várias microrregiões do Estado de Minas Gerais, durante o período de 1974/75 a 1995/96. O ganho genético médio obtido em todo o período foi de $33 \mathrm{~kg} / \mathrm{ha} /$ ano $(0,98 \%)$, sendo altamente significativo ( $\mathrm{P}<0,01)$. O período de 22 anos foi subdividido em duas fases: na primeira (1974/75 a 1979/80), observou-se um ganho de $203 \mathrm{~kg} / \mathrm{ha} /$ ano $(6,06 \%)$, o qual foi altamente significativo, e a segunda fase (1980/81 a 1995/96) apresentou um ganho de $15 \mathrm{~kg} / \mathrm{ha} /$ ano $(0,25 \%)$, o qual não foi significativo. Atribuise o alto ganho da primeira fase à substituição de cultivares tradicionais de porte alto e de baixo potencial produtivo por cultivares melhoradas, como Inca, BG 90-2 e MG 2. Na segunda fase do programa, deu-se um enfoque maior à obtenção de cultivares mais resistentes a doenças e com melhor qualidade de grãos, resultando em ganhos não-significativos quanto à produtividade de grãos.
\end{abstract}

Termos para indexação: Oryza sativa, ganho genético, avaliação de genótipos.

EVALUATION OF THE GENETICAL PROGRESS OBTAINED IN 22 YEARS ON THE IMPROVEMENT OF IRRIGATED RICE IN MINAS GERAIS, BRAZIL

\begin{abstract}
The goal of this work was to evaluate the performance of the genetical improvement program of irrigated rice in the State of Minas Gerais, Brazil. The grain yield data of the advanced comparative trials of both cultivars and lines of irrigated rice, conducted in several regions of the State of Minas Gerais over the period of $1974 / 75$ to $1995 / 1996$ were utilized. The average genetical gain obtained was of $33 \mathrm{~kg} / \mathrm{ha} /$ year $(0.98 \%)$, being highly significant $(\mathrm{P}<0.01)$. The 22 year period was subdivided into two phases: at the first phase (1974/75 to 1979/80), a gain of $203 \mathrm{~kg} / \mathrm{ha} / \mathrm{year}(6.06 \%)$ was noticed, which was highly significant, and the second phase (1980/81 to 1995/96) presented a gain of $15 \mathrm{~kg} / \mathrm{ha} /$ year $(0.25 \%)$ being non significant. The high gain of the first phase is ascribed to the replacement of traditional high size and poor yielding potential for breeding materials such as Inca, BG 90-2 and MG 2. In the second phase of the program, increased attention was given to obtain materials more resistant to diseases and with better grain quality and non-significant gains for yield were obtained.
\end{abstract}

Index terms: Oryza sativa, genetical gain, genotype evaluation.

${ }^{1}$ Aceito para publicação em 24 de novembro de 1998.

${ }^{2}$ Eng ${ }^{\mathrm{a}}$ Agra, M.Sc., Dep. de Biologia, Universidade Federal de Lavras (UFLA), Caixa Postal 37, CEP 37200-000 Lavras, MG. E-mail: pgsantos@ufla.br

${ }^{3}$ Eng. Agr., Dr., Empresa de Pesquisa Agropecuária de Minas Gerais (EPAMIG), Caixa Postal 216, CEP 36570-000 Viçosa, MG. E-mail: plinio@mail.ufv.br

${ }^{4}$ Eng. Agr., Dr., Dep. de Agricultura, UfLA. E-mail aasoares@ufla.br

${ }^{5}$ Eng. Agr., Dr., Embrapa-Centro Nacional de Pesquisa de Arroz e Feijão (CNPAF), Caixa Postal 179, CEP 74001-970 Goiânia, GO. E-mail: peixoto@enpaf.embrapa.br

${ }^{6}$ Eng ${ }^{\mathrm{a}}$ Agr $\stackrel{\mathrm{a}}{ }$, M.Sc., EPAMIG Caixa Postal 176, CEP 37200-000 Lavras, MG. E-mail: epamig@ufla.br

\section{INTRODUÇÃO}

A avaliação de programas de melhoramento genético de diversas espécies de importância econômica, por meio da obtenção de estimativas do progresso genético, tem sido um instrumento muito utilizado pelos melhoristas, pois a partir dessa iniciativa pode-se saber se os programas estão atingindo os objetivos almejados. Caso contrário, novas alternativas devem ser buscadas visando à melhor eficiência e retorno dos recursos investidos em pesquisa. 
Em Minas Gerais, o programa de melhoramento do arroz irrigado por inundação é realizado pela EPAMIG em parceria com Embrapa-Centro Nacional de Pesquisa de Arroz e Feijão (CNPAF) e UFLA. Durante 22 anos de pesquisa, vários materiais foram avaliados e muitas cultivares lançadas, destacando-se a Inca, MG1, MG2, Sapucaí, Urucuia e Capivari, que apresentavam, entre outras características, alto potencial de produtividade de grãos (Soares et al., 1994).

A recomendação ou lançamento de uma nova cultivar no Estado de Minas Gerais passa por testes rigorosos e criteriosos, realizados pelo menos durante três anos, nas principais regiões produtoras de arroz, mediante os ensaios comparativos avançados. A cada ano, novos materiais são introduzidos nos ensaios, para que sejam avaliados em vários locais, eliminando-se os de baixo desempenho produtivo. Assim, é importante que se faça uma avaliação do desempenho do programa de arroz irrigado de Minas Gerais ao longo dos anos, para que se possam direcionar os futuros trabalhos de melhoramento genético, visando ao aumento de produtividade, boa qualidade de grãos e resistência a doenças.

Para avaliar a eficiência de um programa, podem ser usadas várias metodologias com vistas à obtenção da estimativa do progresso genético. Um método que tem sido bastante empregado recentemente em alguns estados pode ser encontrado no trabalho de Breseghello (1995), em que são utilizadas médias ajustadas, caracterizando-se pela eficiência e versatilidade diante de dados desbalanceados.

O presente trabalho teve como objetivo avaliar o desempenho do programa de melhoramento genético do arroz irrigado por inundação, desenvolvido em Minas Gerais, durante o período de 1974 a 1996.

\section{MATERIAL E MÉTODOS}

Obtenção das médias ajustadas e da matriz de covariância

A estimativa do ganho genético foi obtida a partir dos resultados de produtividade de grãos dos ensaios comparativos avançados de avaliação de cultivares e linhagens de arroz irrigado por inundação, conduzidos em
Minas Gerais, no período de 1974/75 a 1995/96. Nesse período, com exceção dos anos de 1974/75 e 1990/91, um grupo de linhagens que não apresentava um bom desempenho era, anualmente, descartado e substituído por outro grupo supostamente superior. As linhagens do ano agrícola 1974/75 foram as mesmas do ano seguinte (1975/76); por isso, as médias dos dois anos foram apresentadas como se fossem um único ano (1974/76). O mesmo ocorreu entre os anos agrícolas 1990/91 e 1991/92, representadas por 1990/92.

O número de ensaios por ano agrícola variou de um a seis; foi analisado um total de 105 ensaios, que haviam sido conduzidos com o delineamento de blocos ao acaso, com quatro repetições.

A análise de variância conjunta foi feita utilizando-se o procedimento GLM (Modelo Linear Generalizado) do SAS (SAS Institute, 1985), obtendo-se o vetor de médias $(\hat{Y})$ ajustadas para efeito de ano, das linhagens e testemunhas avaliadas. A matriz de covariância das médias estimadas foi obtida por:

$\hat{\mathrm{V}}(\underset{\sim}{\mathrm{Y}})=\mathrm{A} \cdot\left(\mathrm{X}^{\prime} \mathrm{X}\right)^{-} \cdot \mathrm{A}^{\prime} \mathrm{QM}_{\mathrm{GA}}$, sendo:

A : matriz de coeficientes das soluções tal que $\hat{Y}=A \theta^{\circ}$ $\theta^{\circ}$ : vetor de soluções de quadrados mínimos do modelo estatístico empregado

$\left(\mathrm{X}^{\prime} \mathrm{X}\right)^{-}$: inversa generalizada da matriz $\mathrm{X}^{\prime} \mathrm{X}$, fornecida, à semelhança de $\theta^{\circ}$, pelo procedimento GLM do SAS.

$\mathrm{QM}_{\mathrm{GA}}$ : estimador do quadrado médio do resíduo da análise de variância.

\section{Estimativa do ganho genético}

Com o vetor de médias ajustadas e a correspondente matriz de estimativas de variâncias e covariâncias, efetuaram-se comparações das médias dos grupos de linhagens anualmente introduzidas $\left(\mathrm{G}_{\text {int }}\right)$ ou eliminadas $\left(G_{\text {eli }}\right)$, ou seja, os contrastes $G_{\text {int }}$ versus $G_{\text {eli }}$, dentro de cada ano, e os respectivos desvios-padrão. Em seguida, obtiveram-se as estimativas de ganho genético médio, conforme metodologia de Breseghello (1995), considerando todo o período estudado, e em duas fases distintas e consecutivas desse período: 1974/75 a 1979/80 e 1980/81 a 1995/96. A primeira fase distingue-se da segunda por ter se caracterizado por uma gradativa substituição das variedades tradicionais por novas linhagens de melhor arquitetura de planta, em teste. 


\section{RESULTADOS E DISCUSSÃO}

Na Tabela 1, estão relacionadas as médias de produtividade de grãos dos grupos de materiais introduzidos $\left(\mathrm{G}_{\text {int }}\right)$ e dos grupos dos eliminados $\left(\mathrm{G}_{\mathrm{eli}}\right)$ a cada ano dos ensaios comparativos avançados. As testemunhas tradicionais foram representadas pelas cultivares IAC 120, IAC 435, Chorinho, Amarelão IAO 2, De Abril e Matão, cuja estimativa da média ajustada foi de $3.393 \mathrm{~kg} / \mathrm{ha}$. Como se pode observar, apenas a média dos materiais introduzidos no primeiro ano (1974/75) não superou a média das testemunhas. Os materiais avaliados neste ano eram pouco produtivos, e entre eles podem-se citar as cultivares americanas Bluebelle e Belle

TABELA 1. Médias de produtividade de grãos (kg/ha) dos grupos de materiais introduzidos $\left(G_{\text {int }}\right)$ e dos grupos de linhagens eliminados $\left(G_{\text {eli }}\right)$ a cada ano; percentual da média dos materiais introduzidos e eliminados em relação à média das testemunhas e contrastes entre os dois grupos.

\begin{tabular}{|c|c|c|c|c|c|}
\hline Ano & $\mathrm{G}_{\mathrm{int}}{ }^{1}$ & $\begin{array}{l}\text { Perc. em } \\
\text { relação às } \\
\text { testemunhas }\end{array}$ & $\mathrm{G}_{\mathrm{eli}}$ & $\begin{array}{l}\text { Perc. em } \\
\text { relação às } \\
\text { testemunhas }\end{array}$ & $\mathrm{G}_{\mathrm{int}}-\mathrm{G}_{\mathrm{eli}}$ \\
\hline $1974 / 76$ & 3350 & $99 \%$ & & & \\
\hline $1976 / 77$ & 4412 & $130 \%$ & 2303 & $68 \%$ & $2110 *$ \\
\hline $1977 / 78$ & 5950 & $175 \%$ & 3903 & $115 \%$ & $2047 *$ \\
\hline $1978 / 79$ & 5364 & $158 \%$ & 4370 & $129 \%$ & $995 *$ \\
\hline $1979 / 80$ & & & 5085 & $150 \%$ & \\
\hline $1980 / 81$ & 5784 & $170 \%$ & 5782 & $170 \%$ & 3 \\
\hline $1981 / 82$ & 5965 & $176 \%$ & 6784 & $200 \%$ & $-820 *$ \\
\hline $1982 / 83$ & 5305 & $156 \%$ & 5863 & $173 \%$ & $-558 *$ \\
\hline $1983 / 84$ & 5453 & $161 \%$ & 5443 & $160 \%$ & 11 \\
\hline $1984 / 85$ & 5429 & $160 \%$ & 4984 & $147 \%$ & $446 *$ \\
\hline $1985 / 86$ & 5920 & $174 \%$ & 5353 & $158 \%$ & $567 *$ \\
\hline $1986 / 87$ & 6158 & $181 \%$ & 5886 & $173 \%$ & 273 \\
\hline $1987 / 88$ & 5607 & $165 \%$ & 6194 & $183 \%$ & $-587 *$ \\
\hline $1988 / 89$ & 5856 & $173 \%$ & 6015 & $177 \%$ & -160 \\
\hline $1989 / 90$ & 6083 & $179 \%$ & 5486 & $162 \%$ & $596 *$ \\
\hline 1990/92 & 6235 & $184 \%$ & 5983 & $176 \%$ & 252 \\
\hline $1992 / 93$ & 5235 & $154 \%$ & 6227 & $184 \%$ & $-992 *$ \\
\hline $1993 / 94$ & 6587 & $194 \%$ & 5710 & $168 \%$ & $876^{*}$ \\
\hline $1994 / 95$ & 5703 & $168 \%$ & 6149 & $181 \%$ & $-446 *$ \\
\hline $1995 / 96$ & 5774 & $170 \%$ & 5434 & $160 \%$ & 340 \\
\hline Média & & & & & 275 \\
\hline
\end{tabular}

Patna. Um avanço bastante expressivo ocorreu nos anos agrícolas de 1976/77 e 1977/78 em que os materiais introduzidos foram, respectivamente, $30 \%$ e $75 \%$ mais produtivos do que as testemunhas, e entre eles estão as linhagens IR 634-9-6-2 e BG 90-2 e as cultivares Inca, IR 841 e IAC 899. Nos anos agrícolas que se sucederam, as médias de produtividades permaneceram mais ou menos constantes, destacando-se o ano agrícola de 1993/94, em que foram introduzidas algumas linhagens bastante produtivas, como a CNA 7857, IAC 1289 e CNA 7809.

Além do processo de introdução de novos materiais, é muito importante o descarte ou eliminação de materiais que não estão contribuindo para melhorar o desempenho do programa de melhoramento. No presente trabalho, pode-se observar que no período compreendido entre 1976/77 e 1978/79, o descarte de materiais pouco produtivos foi eficiente. Isso é corroborado pelo contraste entre genótipos introduzidos e eliminados, em que os valores foram altos e significativos, indicando a superioridade dos materiais introduzidos. Os contrastes negativos e significativos indicam que os materiais eliminados eram superiores aos introduzidos. Possivelmente, os referidos materiais foram eliminados, por serem pouco promissores quanto a características de grãos, ou por se mostrarem susceptíveis a doenças.

Os contrastes entre as médias de produção de grãos dos grupos de genótipos introduzidos e entre as médias dos grupos de materiais eliminados envolvendo os 22 anos são mostradas na Tabela 2 . Nessa tabela, encontram-se ainda os contrastes desses grupos de materiais com a média das testemunhas, identificadas na primeira linha e na primeira coluna. Primeiramente, observam-se os contrastes das médias dos materiais introduzidos, com a média das testemunhas. À exceção do primeiro e terceiro ano agrícola, todos os contrastes foram significativos, o que indica que os materiais introduzidos durante esse período foram superiores aos das testemunhas. Quando se analisa o quarto ano, nota-se que, além da superioridade em relação às testemunhas, os materiais introduzidos neste ano foram significativamente mais produtivos que os dos anos $1(1974 / 75)$ e 3 (1976/77). De maneira geral, todas as introduções feitas nos anos consecutivos 
TABELA 2. Contrastes entre as médias de produtividade de grãos do grupo de materiais introduzidas ( $G_{\text {int }}$ ) na diagonal superior, e entre as médias do grupo de materiais eliminados $\left(G_{\text {eli }}\right)$, na diagonal inferior, em cada ano e contrastes desses grupos com as testemunhas (T), mostrados na primeira linha e primeira coluna (nos anos 2 e 18 não houve introdução e nem eliminação de linhagens nos ensaios).

\begin{tabular}{|c|c|c|c|c|c|c|c|c|c|c|c|c|c|c|c|c|c|c|c|c|c|}
\hline Ano & $\mathrm{T}$ & 1 & 3 & 4 & 5 & 6 & 7 & 8 & 9 & 10 & 11 & 12 & 13 & 14 & 15 & 16 & 17 & 19 & 20 & 21 & 22 \\
\hline $\mathrm{T}$ & & $-43,2$ & 1019 & $2557^{*}$ & $1971^{*}$ & & $2391^{*}$ & $2572^{*}$ & $1912^{*}$ & $2060^{*}$ & $2036^{*}$ & $2527^{*}$ & $2765^{*}$ & $2214^{*}$ & $2463^{*}$ & $2690^{*}$ & $2842^{*}$ & $1842^{*}$ & $3194^{*}$ & $2310^{*}$ & $2381^{*}$ \\
\hline 1 & & & 1062 & $2600^{*}$ & $2014^{*}$ & & $2434^{*}$ & $2615^{*}$ & $1955^{*}$ & $2103^{*}$ & $2079^{*}$ & $2569^{*}$ & $2808^{*}$ & $2257^{*}$ & $2506^{*}$ & $2733^{*}$ & $2885^{*}$ & $1885^{*}$ & $3237^{*}$ & $2353^{*}$ & $2424^{*}$ \\
\hline 3 & -1091 & & & $1438^{*}$ & 952 & & 1372 & $1553^{*}$ & 893 & 1041 & 1017 & $1507^{*}$ & $1746^{*}$ & 1195 & 1443 & $1670^{*}$ & $1823^{*}$ & 823 & $2174^{*}$ & 1290 & 1362 \\
\hline 4 & 510 & & 1601 & & -586 & & -166 & 14 & -646 & -497 & -521 & . & 208 & -343 & -95 & 1 & 284 & -716 & 636 & -248 & -176 \\
\hline 5 & $976^{*}$ & & $2067^{*}$ & 467 & & & 420 & 601 & -60 & 89 & 65 & 555 & 794 & 243 & 491 & 718 & 870 & -130 & $1222^{*}$ & 338 & 410 \\
\hline 6 & $1691^{*}$ & & $2782^{*}$ & 1181 & 715 & & & & & & & & & & & & & & & & \\
\hline 7 & $2388^{*}$ & & $3479^{*}$ & $1878^{*}$ & $1412^{*}$ & 697 & & 181 & 480 & 331 & -355 & 135 & 374 & 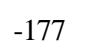 & 71 & 298 & 450 & -550 & 802 & -82 & -10 \\
\hline 8 & $3391^{*}$ & & $4482^{*}$ & $2881^{*}$ & $2415^{*}$ & $1700^{*}$ & $1003^{*}$ & & -660 & -511 & -536 & -45 & 194 & -358 & -109 & 118 & 270 & -730 & 622 & -262 & -191 \\
\hline 9 & $2470^{*}$ & & $3561^{*}$ & $1960^{*}$ & $1493^{*}$ & 779 & 82 & $-921^{*}$ & & 149 & 125 & 615 & 854 & 303 & 551 & 778 & 930 & -70 & $1282^{*}$ & 398 & 469 \\
\hline 10 & $2049^{*}$ & & $3140^{*}$ & $1539^{*}$ & 1073 & 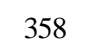 & -339 & $-1342^{*}$ & -421 & & -24 & 466 & 705 & 154 & 402 & 629 & $781^{*}$ & -219 & $1133^{*}$ & 249 & 321 \\
\hline 11 & $1590^{*}$ & & $2681^{*}$ & 1080 & 614 & -101 & -798 & $-1801^{*}$ & -880 & -459 & & 490 & 129 & 178 & 426 & ב5ת & $805^{*}$ & -195 & $1157^{*}$ & 273 & 344 \\
\hline 12 & $1959^{*}$ & & $3050^{*}$ & 1450 & 983 & 268 & -429 & $-1432^{*}$ & -510 & -90 & 369 & & 239 & -312 & -64 & 163 & 315 & -685 & 667 & -217 & -154 \\
\hline 13 & $2492^{*}$ & & $3583^{*}$ & $1982^{*}$ & $1516^{*}$ & 8 & 104 & -899 & 22 & 443 & 902 & 533 & & -551 & -303 & -76 & 76 & -924 & 428 & -456 & -384 \\
\hline 14 & $2801^{*}$ & & $3892^{*}$ & $2291^{*}$ & $1825^{*}$ & 1110 & 413 & -590 & 331 & 752 & $1211^{*}$ & $842^{*}$ & 309 & & 248 & 475 & 627 & -373 & 979 & 95 & 167 \\
\hline 15 & $2622^{*}$ & & $3713^{*}$ & $2112^{*}$ & $1646^{*}$ & 931 & 234 & -769 & 152 & 573 & $1032^{*}$ & 663 & 130 & -179 & & 227 & 379 & -621 & $731^{*}$ & -153 & -82 \\
\hline 16 & $2093^{*}$ & & $3184^{*}$ & $1583^{*}$ & $1117^{*}$ & 402 & -295 & $-1298^{*}$ & -377 & 44 & 503 & 134 & -399 & -708 & -529 & & 152 & -848 & 504 & -380 & -309 \\
\hline 17 & $2590^{*}$ & & $3680^{*}$ & $2080^{*}$ & $1613^{*}$ & 898 & 201 & -802 & 120 & 540 & 999 & 630 & 91 & -212 & -33 & 496 & & $-1000^{*}$ & 352 & -532 & -461 \\
\hline 19 & $2834^{*}$ & & $3924^{*}$ & $2324^{*}$ & $1857^{*}$ & 1142 & 445 & -558 & 364 & 784 & $1243^{*}$ & $874^{*}$ & 341 & 32 & 212 & $741^{*}$ & 244 & & $1352^{*}$ & 468 & 539 \\
\hline 20 & $2317^{*}$ & & $3408^{*}$ & $1807^{*}$ & $1341^{*}$ & 626 & -71 & $-1074^{*}$ & -153 & 268 & 727 & 358 & -175 & -484 & -305 & 224 & -272 & -517 & & $-884^{*}$ & $-813^{*}$ \\
\hline 21 & $2756^{*}$ & & $3846^{*}$ & $2246^{*}$ & $1779^{*}$ & 1064 & ( & -636 & 200 & 706 & $1165^{*}$ & $796^{*}$ & 263 & -46 & 134 & 662 & 166 & -78 & 439 & & 72 \\
\hline 22 & $2041^{*}$ & & $3132^{*}$ & 1531 & 1065 & 350 & -347 & $-1350^{*}$ & -429 & -8 & 451 & 81 & -451 & -760 & -581 & -52 & -549 & $-793^{*}$ & -276 & $-715^{*}$ & \\
\hline
\end{tabular}

* Significativos a $5 \%$ pelo teste de Tukey 
foram estatisticamente superiores aos materiais do primeiro ano, e somente algumas dessas introduções foram superiores em relação ao ano 3. Outros poucos contrastes significativos podem ser observados, e em alguns casos o contraste foi negativo, a exemplo dos materiais introduzidos no ano 19 (1992/93), que se mostraram inferiores aos materiais do ano 17 (1990/91). Isso salienta mais uma vez que não houve grandes avanços para produtividade no decorrer do programa, a partir de $1977 / 78$. Um destaque pode ser dado para o ano 20 (1993/94), em que os contrastes significativos e positivos indicam a superioridade dos materiais introduzidos neste ano em relação aos anos anteriores: $5,9,10,11,15$ e 19. Essa tendência não foi confirmada nos anos 21 e 22 .

Em relação aos contrastes das médias dos materiais eliminados, apresentados abaixo da diagonal da Tabela 2, pode-se observar que a partir do quinto ano (1978/79) a produtividade média de todos os materiais eliminados durante 17 anos foi estatisticamente superior à produtividade média das testemunhas. O mesmo aconteceu quando esses materiais foram comparados no terceiro ano. Nota-se certa tendência também quanto aos anos 4 e 5, ou seja, no geral, os materiais eliminados a partir do quinto ano apresentaram médias superiores aos materiais dos anos 3, 4 e 5. Apesar de os materiais eliminados apresentarem médias altas, pode-se constatar (Tabela 1) que a média dos grupos de materiais introduzidos foi superior à do grupo de materiais eliminados, como pode ser visto pelo valor médio do contraste $(275 \mathrm{~kg} / \mathrm{ha})$. Possivelmente, os materiais eliminados que apresentavam médias de produtividade altas possuíam outras características indesejáveis, principalmente qualidade de grãos.

A Tabela 3 contém as médias ajustadas de produtividade de grãos dos materiais avaliados nos ensaios anuais, sua porcentagem em relação à média das testemunhas, o ganho anual e o ganho médio anual corrigido. Observa-se que a média dos materiais avaliados em 1976/77 mostrou-se 20,5\% superior à média das testemunhas. Quanto aos anos consecutivos, houve um incremento maior, destacando-se 1993/94, cujos materiais foram $83,6 \%$ mais produtivos que as testemunhas.
Nota-se que os ganhos anuais variaram de -361 a $1.494 \mathrm{~kg} / \mathrm{ha}$, o que mostra uma amplitude de variação muito grande. Os ganhos foram altos e significativos no início do período de 1976/77 até o começo da década de 80; a partir de então, reduziram-se, e alguns até foram negativos. Esse fato é reforçado pelo contraste entre $\mathrm{G}_{\text {int }}$ e $\mathrm{G}_{\text {eli }}$ nos anos agrícolas de 1981/82 e 1982/83, que se mostraram negativos e significativos, o que confirma que os materiais eliminados eram mais produtivos que os introduzidos. O restante do período foi marcado por alternâncias entre ganhos positivos e negativos; isto indica que houve instabilidade do programa durante esses últimos anos.

O ganho médio anual foi de $33 \mathrm{~kg} /$ ha e significativo pelo teste de $\mathrm{t}$, a $1 \%$ de probabilidade. Em relação à média $(3.350 \mathrm{~kg} / \mathrm{ha})$ do grupo de materiais do início do período estudado (1974/75), o ganho genético representou, em termos percentuais, um incremento médio de $0,98 \%$ /ano na produtividade. Esse ganho foi superior ao obtido por Breseghello (1995) no que diz respeito ao arroz irrigado no Nordeste do Brasil, que foi de $0,77 \%$. Por outro lado, outros autores obtiveram ganhos superiores: Silva (1996) encontrou um ganho de $2,68 \%$ no tocante ao arroz irrigado, no Espírito Santo; Abbud (1991), no Paraná, obteve um ganho médio de $1,35 \%$.

O período envolvido nesse estudo foi dividido em duas fases: a primeira, correspondendo aos anos de 1974/75 a 1979/80; e a segunda fase, representada pelos anos de 1980/81 a 1995/96. Pode-se constatar, na Tabela 3 , que o ganho médio percentual da primeira fase foi de $6,06 \%$, o qual foi altamente significativo e bastante superior ao ganho médio percentual encontrado na segunda fase, que foi de apenas $0,25 \%$, e não-significativo. Uma explicação plausível é a de que na primeira fase, inúmeras cultivares do grupo tradicional participaram do programa, e que após serem substituídas por genótipos melhorados, implicaram ganhos menores ou quase nulos. Além do mais, na segunda fase houve maior necessidade de se considerar como objetivo maior do programa a seleção com vistas a outras características, tais como qualidade dos grãos e resistência a enfermidades, principalmente à brusone; além disso, deve ser salientado o alto grau de parentesco das linhagens e cultivares avaliadas 
atualmente (Rangel et al., 1996). Isso não torna o programa de arroz irrigado ineficiente; ao contrário, mostra a preocupação dos pesquisadores em atender às exigências tanto do mercado quanto dos produtores. Haja vista que o sucesso do programa pode ser evidenciado por meio das cultivares lançadas, e é resultante da união de esforços de várias instituiçõos cooperativas. Dentre esses materiais, podem-se destacar as cultivares: Capivari, Urucuia e Sapucaí, que associam alto potencial produtivo e boa qualidade de grãos.

Novas estratégias estão sendo adotadas pelo programa de melhoramento genético do arroz irrigado, para obtenção de materiais mais produtivos, resistentes a doenças e com alta qualidade de grãos. Entre elas, podem-se citar o programa de seleção recorrente e o programa para obtenção de híbridos de arroz.

As médias de produtividade de grãos de algumas cultivares de interesse, que contribuíram significativamente para o aumento da produção de grãos no Estado são apresentadas na Tabela 4. As médias dos materiais seguidas pela letra "a" diferem estatisticamente da média das testemunhas, e as seguidas de "b" diferem estatisticamente da cultivar Inca. Observa-se que a cultivar Inca, lançada em 1982, e

TABELA 3 . Médias ajustadas de produtividade de grãos (kg/ha) dos grupos dos ensaios anuais, percentual em relação a média do grupo das testemunhas, ganhos anuais \pm desvio-padrão e ganho médio corrigido.

\begin{tabular}{|c|c|c|c|c|}
\hline Ano & Médias ajustadas & $\begin{array}{l}\text { Perc. em relação às } \\
\text { testemunhas }\end{array}$ & $\begin{array}{c}\text { Ganho anual } \\
(\mathrm{kg} / \mathrm{ha})\end{array}$ & $\begin{array}{c}\text { Ganho/desvio- } \\
\text { padrão }^{1}\end{array}$ \\
\hline Testemunhas & 3393 & 100 & & \\
\hline $1974 / 75$ & 3350 & 99 & & \\
\hline $1976 / 77$ & 4091 & 120 & 740 & 3,4 \\
\hline $1977 / 78$ & 5585 & 164 & 1494 & 5,7 \\
\hline $1978 / 79$ & 5833 & 172 & 249 & 3,4 \\
\hline $1979 / 80$ & 6016 & 177 & 183 & 2,8 \\
\hline $1980 / 81$ & 6039 & 178 & 22 & 0,3 \\
\hline $1981 / 82$ & 5893 & 174 & -145 & 4,5 \\
\hline $1982 / 83$ & 5578 & 164 & -315 & 2,0 \\
\hline $1983 / 84$ & 5561 & 164 & -17 & 0,1 \\
\hline $1984 / 85$ & 5690 & 168 & 130 & 1,1 \\
\hline $1985 / 86$ & 6002 & 177 & 312 & 2,8 \\
\hline $1986 / 87$ & 6056 & 178 & 54 & 0,8 \\
\hline $1987 / 88$ & 5950 & 175 & -106 & 1,7 \\
\hline $1988 / 89$ & 5857 & 173 & -93 & 0,8 \\
\hline $1989 / 90$ & 6081 & 179 & 224 & 2,6 \\
\hline $1990 / 91$ & 6144 & 181 & 63 & 1,1 \\
\hline $1992 / 93$ & 5937 & 175 & -207 & 3,6 \\
\hline $1993 / 94$ & 6231 & 184 & 294 & 4,4 \\
\hline $1994 / 95$ & 5870 & 173 & -361 & 4,0 \\
\hline $1995 / 96$ & 5978 & 176 & 108 & 1,7 \\
\hline Ganho médio ${ }^{2}$ & & & & $\begin{array}{c}33,0 \pm 8,6 * * \\
(0,98 \%)\end{array}$ \\
\hline \multicolumn{4}{|c|}{$\begin{array}{l}\text { Ganho anual médio primeira fase } \\
(1974 / 75 \text { a } 1979 / 80)\end{array}$} & $\begin{array}{c}202,9 \pm 28,4^{* *} \\
(6,06 \%)\end{array}$ \\
\hline \multicolumn{4}{|c|}{$\begin{array}{l}\text { Ganho anual médio segunda fase } \\
(1979 / 80 \text { a } 1995 / 96)\end{array}$} & $\begin{array}{c}14,8 \pm 9,5^{\mathrm{ns}} \\
(0,25 \%)\end{array}$ \\
\hline
\end{tabular}

1 Valores acima de 2 desvios-padrão são considerados estatisticamente significativos (El-Rouby et al., 1973)

2 Corrigido para 22 anos

** Significativo a $1 \%$ de probabilidade, pelo teste $\mathrm{t}$. 
com característica regular (grão agulhinha, mas baixo teor de amilose) de grão, foi $80 \%$ mais produtiva que a média das testemunhas. A Inca deteve a hegemonia no Estado, por vários anos, mas hoje está sendo substituída por novas cultivares. As cultivares MG 1 e MG 2, lançadas em 1985 , também mostraram-se superiores às testemunhas, além de apresentarem melhor qualidade de grãos que a cultivar Inca. Ocupam hoje pequena área de plantio no Estado e estão também sendo substituídas.

As cultivares mais recentes, que vêm substituindo as anteriores, são a Capivari, a Urucuia e a Sapucaí, lançadas simultaneamente em 1994. Observa-se que suas superioridades em relação às testemunhas são, respectivamente, de $81 \%$, 79\% e $75 \%$. Quando comparadas com as cultivares Inca, MG 1 e MG 2 , apresentam produtividades semelhantes, e destacam-se destas pela melhor qualidade de grãos, principalmente a Sapucaí, e pela resistência à brusone, sobretudo a cultivar Urucuia. Maior destaque pode ser dado à linhagem BG 90-2, que foi $100 \%$ mais produtiva que as testemunhas; este material só não chegou a ser lançado em Minas Gerais em virtude de possuir grãos de baixa qualidade comercial. A cultivar BR-IRGA 409 apresentou-se estatisticamente inferior à cultivar Inca em produtividade de grãos.

TABELA 4. Médias de produtividade de grãos (kg/ha) do grupo das testemunhas e das cultivares de interesse e percentual em relação ao grupo das testemunhas.

\begin{tabular}{lcc}
\hline Materiais & Médias $^{1}$ & $\begin{array}{c}\text { Perc. em relação } \\
\text { às testemunhas }\end{array}$ \\
\hline Testemunhas & 3.393 & 100 \\
IR 841 & $5.403 \mathrm{a}$ & 159 \\
Inca & $6.109 \mathrm{a}$ & 180 \\
MG 1 & $5.965 \mathrm{a}$ & 176 \\
MG 2 & $6.018 \mathrm{a}$ & 177 \\
BG 90-2 & $6.784 \mathrm{a}$ & 200 \\
BR-IRGA 409 & $4.802 \mathrm{~b}$ & 142 \\
Capivari & $6.145 \mathrm{a}$ & 181 \\
Urucuia & $6.080 \mathrm{a}$ & 179 \\
Sapucaí & $5.940 \mathrm{a}$ & 175 \\
Jequitibá & $5.944 \mathrm{a}$ & 175 \\
\hline
\end{tabular}

${ }^{1}$ Médias seguidas de "a" diferem significativamente da média das testemunhas e seguidas de "b" diferem estatisticamente da média da cultivar Inca, pelo teste de Tukey, a 5\% de probabilidade.
As cultivares atualmente plantadas apresentam produtividades semelhantes à cultivar Inca, lançada há 15 anos. A Jequitibá, lançada em 1997, é a primeira cultivar precoce de arroz irrigado em Minas Gerais, e embora tenha ciclo curto, possui potencial de produtividade de grãos semelhante aos das demais.

Os contrastes entre as médias das testemunhas, médias das cultivares lançadas e médias das linhagens elites são apresentados na Tabela 5. As linhagens elites são as que continuam sendo avaliadas pelo programa de melhoramento. Nota-se que os dois contrastes obtidos em relação à média das testemunhas são altos e significativos, tanto em relação às cultivares lançadas $\left(2.730^{*} \mathrm{~kg} / \mathrm{ha}\right)$ como em relação às linhagens-elite $\left(2.879^{*} \mathrm{~kg} / \mathrm{ha}\right)$ o que indica o sucesso do programa na obtenção e lançamento de materiais produtivos. $\mathrm{O}$ contraste entre a média das cultivares lançadas e a média das linhagens-elite, por sua vez, foi baixo e não-significativo. Isso mostra que o ganho para produtividade atualmente não tem sido satisfatório, e as linhagens-elite não têm superado as cultivares já lançadas. Novamente, isso pode ser justificado pela importância que o programa vem dando para seleção de outras características, que não a produtividade de grãos. Corroborando a discussão anterior, deve-se salientar mais uma vez a necessidade de estabelecer novas estratégias de melhoramento visando à obtenção de cultivares superiores às lançadas no Estado, pois sabe-se que o arroz irrigado ainda tem potencial

TABELA5. Contrastes entre os grupos das testemunhas, cultivares lançadas e linhagenselite.

\begin{tabular}{lccc}
\hline \multirow{2}{*}{ Grupos } & Médias & \multicolumn{2}{c}{ Contrastes } \\
\cline { 3 - 4 } & & $\begin{array}{c}\text { Cultivares } \\
\text { lançadas }\end{array}$ & $\begin{array}{c}\text { Linhagens- } \\
\text { elite }\end{array}$ \\
\hline Testemunhas & 3393 & $2730^{*}$ & $2879 *$ \\
Cultivares lançadas $^{1}$ & 6123 & & $150^{\mathrm{ns}}$ \\
Linhagens-elite $^{2}$ & 6272 & & \\
\hline
\end{tabular}

${ }^{1}$ Cultivares lançadas: Inca, MG 1, MG 2, Urucuia, Capivari, Sapucaí e Jequitibá.

2 Linhagens-elite: PR 380, CNA 8033, CNA 7204, IAC 1289, PR 349, CNA 7857, CNA 8041, IAPAR 58, CNA 7556 e CNA 7553.

* Significativo a $5 \%$ de probabilidade, pelo teste de Tukey. 
produtivo e variabilidade suficiente para ser explorada.

\section{CONCLUSÕES}

1. O programa de melhoramento genético do arroz irrigado desenvolvido em Minas Gerais no período de 1974/75 a 1995/96 foi eficiente para aumentar o potencial de produção de grãos dos novos materiais apenas nos cinco primeiros anos.

2. A estabilização da produtividade dos materiais avaliados a partir da década de oitenta deve-se, entre outros fatores, à concentração de esforços para melhoria da qualidade dos grãos e ao aumento da resistência a doenças, sobretudo à brusone.

\section{AGRADECIMENTOS}

À Fundação de Amparo à Pesquisa no Estado de Minas Gerais (FAPEMIG) e à Embrapa, pelo financiamento do programa de melhoramento genético do arroz desenvolvido em Minas Gerais.

\section{REFERÊNCIAS}

ABBUD, N.S. Melhoramento genético do arroz de sequeiro (Oryza sativa L.) no Estado do Paraná. Piracicaba: ESALQ, 1991. 141p. Tese de Doutorado.
BRESEGHELLO, F. Ganhos para produtividade pelo melhoramento genético do arroz irrigado no Nordeste do Brasil. Goiânia: UFG, 1995. 93p. Dissertação de Mestrado.

EL-ROUBY, M.M.; MORAYEM, Y.S.; NAWAR, A.A. Estimation for genetic variance and its components in maize under stress and non-stress environments. I - Planting date. Egyptian Journal of Genetics and Cytology, v.2, p.10-19, 1973.

RANGEL, P.H.N.; GUIMARÃES, E.P.; NEVES, P.F.C. Base genética das cultivares de arroz (Oryza sativa L.) irrigado do Brasil. Pesquisa Agropecuária Brasileira, Brasília, v.31, n.5, p.349-357, maio 1996.

SAS INSTITUTE. SAS user's guide: statistics, version 5. 5.ed. Cary, NC, 1985. 956p.

SILVA, A.F. Contribuição do melhoramento genético do arroz irrigado por inundação para rendimento de grãos, no período de 1983/84 a 1994/95, no Estado do Espírito Santo. Lavras: UFLA, 1996. 108p. Tese de Doutorado.

SOARES ,A.A.; RAMALHO, M.A.P.; SOUSA, A.F. de Estimativa do progresso genético obtido pelo programa de melhoramento de arroz irrigado da década de oitenta. Pesquisa Agropecuária Brasileira, Brasília, v.29, n.1, p.97-104, jan. 1994. 